\title{
Exothermic Behaviors of Mechanically Abused Lithium-Ion Batteries with
}

\section{Dibenzylamine}

\author{
Yang Shi ${ }^{1}$, Daniel J. Noelle ${ }^{1}$, Meng Wang ${ }^{2}$, Anh V. Le ${ }^{2}$, Hyojung Yoon, ${ }^{3}$ Minghao Zhang, ${ }^{3}$ Y. \\ Shirley Meng ${ }^{1,3}$, Yu Qiao ${ }^{1,2, *}$ \\ ${ }^{1}$ Program of Materials Science and Engineering, University of California - San Diego, La \\ Jolla, CA 92093, U.S.A. \\ ${ }^{2}$ Department of Structural Engineering, University of California - San Diego, La Jolla, CA \\ 92093-0085, U.S.A. \\ ${ }^{3}$ Department of NanoEngineering, University of California - San Diego, La Jolla, CA 92093- \\ 0448, U.S.A. \\ *Corresponding author. Phone: +1-858-534-3388; Email: yqiao@ucsd.edu
}

\begin{abstract}
A thermal-runaway retardant (TRR) of lithium-ion batteries (LIBs), dibenzylamine (DBA), is investigated. In a TRR-modified LIB, DBA can be encapsulated in packages made of inert materials. When the LIB is subjected to mechanical abuse, the packages would be broken apart and the TRR is released. In nail penetration and impact tests, addition of $4 \mathrm{wt} \% \mathrm{DBA}$ reduces the temperature increase of fully charged LIR-2450 cells by nearly $50 \%$. The influence of TRR packages on the cycling performance of LIBs is negligible. The working mechanism of DBA is associated with the decrease in electrolyte conductivity, the increase in charge transfer resistance, and the reduction in lithium ion $\left(\mathrm{Li}^{+}\right)$transference numbers.
\end{abstract}

Keywords: Lithium-ion battery; thermal runaway; safety; conductivity; electrolyte 


\section{Introduction}

Thermal runaway imposes significant challenges to large-scale lithium-ion batteries (LIBs). The working temperature of a LIB is usually around room temperature [1]. Upon mechanical abuse such as an impact or nail penetration, the LIB cell components may fail and internal short circuits could be formed [2]. As a result, a series of exothermic reactions would take place and the local temperature can rapidly increase by $100-200{ }^{\circ} \mathrm{C}$ in less than one minute [3].

Great efforts have been made to enhance the safety of LIBs. A common approach to suppress thermal runaway is to embed thermally triggered safety components into LIBs, such as trilayer separators that can close their pores when the internal temperature reaches the melting point of the middle layer, preventing further ion transport between electrodes $[4,5]$; low-melting-point microspheres that can cover the anode surface when they melt, preventing further ion disintercalation at the electrode-electrolyte interface [6]; positive-temperaturecoefficient (PTC) additives that drastically increase the internal impedance at $110-150{ }^{\circ} \mathrm{C}[7$ 10]; microcapsules that release fire extinguishing agents at $100-130{ }^{\circ} \mathrm{C}$ [11]; and thermally polymerizable monomers that thickens electrolyte [12]. One major issue of these thermalrunaway mitigation mechanisms is that they are activated only after the local temperature rises to above $90{ }^{\circ} \mathrm{C}$, which is dangerously close to the acceleration point of the exothermic reactions [13]. Researchers have also investigated flame retardant additives [14-18] that can 
reduce the electrolyte flammability, yet the battery performance is usually negatively affected [19]. Other approaches include electrode coating and doping that improve the thermal stability of the electrodes [20-26], but extensive fundamental study is still needed to enhance their efficacy and efficiency.

Mechanically triggered thermal-runaway mitigation mechanisms recently received increasing attention [27-29]. For instance, if a thermal-runaway retardant (TRR) is encapsulated in mechanically responsive packages made of materials inert to the battery environment, upon external mechanical loadings the packages can be broken apart and release the TRR. This mechanism allows for the use of aggressive chemicals to suppress the short circuit discharge and the subsequent exothermic phenomena, immediately after the battery is damaged, even before temperature increase begins. The main challenge is that the TRR must be highly efficient, such that it does not result in much increase in cell mass or volume. In this work, we investigate dibenzylamine (DBA) as a TRR candidate. The influence of TRR-containing packages on the cycling performance of LIBs is also evaluated.

\section{Experimental}

\subsection{Nail penetration test}


Xiamen Tob $140 \mathrm{mAh} / \mathrm{g}$ LIR-2450 rechargeable LIB cells, with the diameter of $24 \mathrm{~mm}$ and the thickness of $5 \mathrm{~mm}$, were charged by constant current-constant voltage algorithm using a MTI BST8-WA Battery Analyzer to $4.3 \mathrm{~V}$ at C/5, with the cut-off current of C/50. The charged cells were disassembled and the electrode stacks together with the electrolyte were harvested in an Argon-filled glovebox $\left(\mathrm{H}_{2} \mathrm{O}<0.5 \mathrm{ppm}\right)$. Empty type-2450 cell cases were modified, with two holes drilled in the cathode-side shell and covered with Kapton tapes. The harvested electrodes and electrolyte were re-assembled in the modified cell cases in the glovebox. The Kapton tapes were removed and two Tygon tubes were inserted into the holes and sealed with vacuum grease. Two thermocouples (Omega TT-K-40-25 type-K gauge 40) were attached to the upper and bottom surfaces of the cell case, respectively, $\sim 7 \mathrm{~mm}$ away from the centers, and connected to a temperature logger (Omega OM-EL-USB-TC).

The cell was affixed to a polymethyl methacrylate (PMMA) holder and a steel nail was driven through the cell by a type-5582 Instron machine at the speed of $5 \mathrm{~mm} / \mathrm{s}$. After the nail penetrated the cell, the compression plate of the Instron machine was rapidly moved back, leaving the nail inside the cell. The nail diameter was $3.4 \mathrm{~mm}$. Immediately prior to the nail penetration, $100 \mu \mathrm{L}$ DBA (97\%, Sigma Aldrich) had been injected by a syringe into the modified cell through the Tygon tubing. In the reference test, the same amount of pristine electrolyte was injected into the cell. 
To better understand the efficiency of DBA, nail penetration tests were also carried out on unmodified LIR-2450 cells at various states of charge (SOC). The unmodified LIR-2450 cells at various SOC were prepared by discharging LIB cells that had been fully charged to $4.3 \mathrm{~V}$ to various cut-off discharge capacities of $35 \mathrm{mAh}, 70 \mathrm{mAh}, 105 \mathrm{mAh}$ and $140 \mathrm{mAh}$, respectively.

\subsection{Impact test}

The LIR-2450 cells were charged to $4.3 \mathrm{~V}$ and the electrodes together with electrolyte were harvested through the same procedure as described in Section 2.1. Polyethylene/Aluminum/Polyester (PAP) trilayer (ULINE S-16893) was folded and heat sealed to form packages using an impulse sealer (Mcmaster-Carr), with $115 \mu \mathrm{L}$ DBA or pristine electrolyte sealed inside. The packages were first at rest in the glovebox vacuum antechamber overnight, and then transferred into the glovebox for the subsequent cell assembly. The harvested electrodes and electrolyte were re-assembled into an empty type2450 cell case, with a DBA- or electrolyte-containing package sandwiched between the top shell and the electrode. The cells containing electrolyte packages were used as reference samples.

Impact tests on the re-assembled LIB cells were performed in a table-top drop tower consisting of a stainless steel base and a polycarbonate track [27]. A stainless steel ball with 
the diameter of $6.35 \mathrm{~mm}$ was affixed at the center of the upper surface of the LIB cell. A polyurethane cover guided a stainless steel rod; the diameter of the rod was $12.7 \mathrm{~mm}$ and the length was $50.8 \mathrm{~mm}[28,29]$. The rod was placed on top of the steel ball. A cylindrical stainless steel hammer with the mass of $7.7 \mathrm{~kg}$ was dropped onto the rod. The drop distance was $18 \mathrm{~cm}$. A type-K thermocouple was attached to the outer surface of the anode-side shell and the temperature was recorded in the same way as described in Section 2.1.

\subsection{Characterization of cycling performance}

Type-2016 coin cells were assembled to evaluate the influence of DBA-containing packages on the cycling performance. Cathode films were prepared by thoroughly mixing $\mathrm{LiNi}_{0.5} \mathrm{Co}_{0.2} \mathrm{Mn}_{0.3} \mathrm{O}_{2}$ (TODA America), polyvinylidene fluoride (Kynar 710), and carbon black (Timcal Super C65) powders with the mass ratio of 93:4:3. Slurries were produced in 1-Methyl-2-pyrrolidinone (Sigma Aldrich), cast on aluminum foil using a doctor blade, and dried under vacuum at $80{ }^{\circ} \mathrm{C}$ for 24 hours. The electrode films had an active mass loading of about $6 \mathrm{mg} / \mathrm{cm}^{2}$. Disk cathodes were cut, compressed using a rolling mill, dried again under vacuum for 4 hours, and transferred to an Argon-filled glovebox $\left(\mathrm{H}_{2} \mathrm{O}<0.1 \mathrm{ppm}\right)$ for cell assembly. Small PAP packages containing $\sim 5 \mu \mathrm{L}$ DBA were sealed, vacuum-dried overnight, and attached to the inner surfaces of type-2016 cell cases using Kapton tapes. To assemble the cells, semicircular pieces of cathodes and lithium metal disk anodes were used. The electrolyte was $1 \mathrm{M} \mathrm{LiPF}_{6}$ in ethylene carbonate and ethyl methyl carbonate (EC: EMC 1:1 
$\mathrm{wt} \%$ ) and the separators were trilayer PP/PE/PP membranes (Celgard 2320). The coin cells were allowed to rest for 2 hours before the electrochemical tests were performed. Galvanostatic charge-discharge was carried out using a BST8-WA Battery Analyzer. The cells were charged and discharged at $\mathrm{C} / 10\left(1 \mathrm{C}=200 \mathrm{~mA} \mathrm{~g}^{-1}\right)$ for the first cycle, followed by charging and discharging at $1 \mathrm{C}$ in the potential range of 3-4.3 $\mathrm{V}$ for all the subsequent cycles. Reference cells with the same semicircular cathodes were also assembled and cycled without DBA-containing packages.

\subsection{Interaction of DBA with electrodes}

To understand the interaction between DBA and the electrodes, fully charged LIR 2450 cells were disassembled and the cathode and anode films were separated. About $100 \mu \mathrm{L}$ DBA was dropped onto the harvested cathode or anode and the local temperature was recorded using the same thermocouple as in Section 2.1.

In addition, type-2016 coin cells were assembled in a similar way as in Section 2.3, without the PAP packages. The coin cells were allowed to rest for 2 hours and charged to 4.3 $\mathrm{V}$ at $\mathrm{C} / 10$. The charged cells were disassembled in the glovebox and the cathode disks were fully washed with dimethyl carbonate (DMC). The charged cathode disks were divided into two groups. The first group were soaked in $15 \mathrm{~mL} \mathrm{DBA}$ for $20 \mathrm{~min}$, followed by repeated rinsing with electrolyte and DMC. The washed cathode disks were re-assembled into coin 
cells with Li disks; the cells were discharged to $3 \mathrm{~V}$ at $\mathrm{C} / 10$ after resting for 2 hours. The second group were soaked in $100 \mu \mathrm{L}$ DBA for $20 \mathrm{~min} .{ }^{1} \mathrm{H}$ NMR spectra of DBA before and after the interaction with charged cathodes were recorded by a Varian Mercury Plus $400 \mathrm{MHz}$ NMR spectrometer in $\mathrm{CDCl}_{3}$. Mass spectra of DBA before and after the interaction with charged cathodes were obtained by a Thermo LCQdeca molecular mass spectrometer.

\subsection{Interaction of DBA with electrolyte}

The ionic conductivities of electrolytes containing various amounts of DBA (0-40 wt \%) were measured by a conductivity meter (DDS 307A, Shanghai Yoke Instrument). Type-2016 coin cells were assembled through a similar procedure as in Section 2.4; the electrolyte was either pristine or modified with DBA. The coin cells were cycled at $1 \mathrm{C}$ after resting for 2 hours. Electrochemical impedance spectroscopy (EIS) measurements were carried out before and after cycling in the frequency range of $10^{6} \mathrm{~Hz}$ to $10^{-2} \mathrm{~Hz}$ with the signal amplitude of 10 $\mathrm{mV}$, using a Solartron Impedance/Gain-Phase Analyzer.

To measure the $\mathrm{Li}^{+}$transference numbers of pristine and DBA-modified electrolytes, $\mathrm{Li}$ metal symmetric cells were assembled. Type-2032 cell cases were used due to the increase in the thickness of cell components. Two Li metal disks were separated by a PP/PE/PP membrane, with a stainless steel spacer and a spring to ensure the tight contact between the components. The electrolytes under investigation were pristine reference $\left(1 \mathrm{M} \mathrm{LiPF}_{6}\right.$ in EC: 
EMC 1:1 wt $\%$ ) and $5 \mathrm{wt} \%$ DBA modified electrolyte. Potentiostatic polarization experiments were performed on the assembled coin cells with a constant voltage of $10 \mathrm{mV}$ by an Arbin BT2000 battery testing system, until a steady-state current was reached. EIS measurements were carried out before and after the polarization.
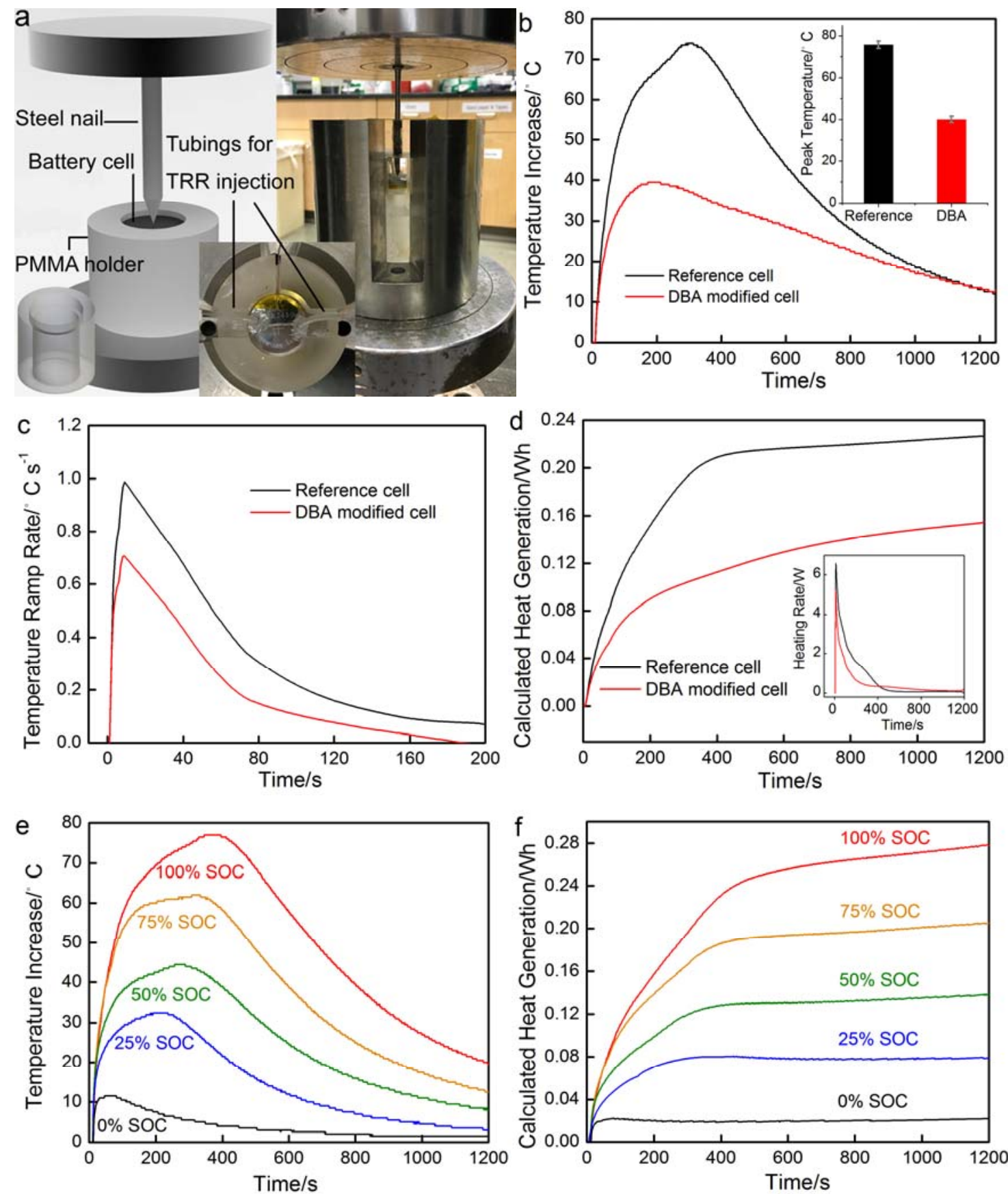
Fig.1 (a) The nail penetration test setup; the bottom-left inset shows the shape of PMMA holder; the middle inset shows the top view of a coin cell. (b) Typical temperature profiles of nail penetration tests on the reference and the DBA-modified cells; the inset shows the peak temperatures with error bars. (c) The temperature ramp rates in the first $200 \mathrm{sec}$. in nail penetration tests. (d) Generated heat of the reference and the DBA-modified cells, calculated from Eq.(2); the inset shows the heating rate. (e) Typical temperature profiles and (f) the generated heat of reference LIR-2450 cells at various SOC.

\section{Results and Discussion}

Nail penetration creates a short circuit with consistent discharge dynamics. Fig. 1a shows the experimental setup. The DBA amount is $4 \mathrm{wt} \%$ of the total mass of electrodes, current collectors, separator, and electrolyte. The measured temperature profiles of the two thermocouples respectively attached to the top and bottom surfaces of LIB cells are similar, with the difference less than $1-2{ }^{\circ} \mathrm{C}$. Figure 1b shows typical temperature profiles measured from the top surface. The addition of DBA reduces the temperature increase $\left(\Delta T_{\max }\right)$ by about $50 \%$, from $\sim 75{ }^{\circ} \mathrm{C}$ in reference cells to $\sim 40{ }^{\circ} \mathrm{C}$ in DBA-modified cells. The temperature ramp rates (Fig. 1c) are calculated by differential analysis of the temperature profiles. Both reference and DBA-modified cells reach their maximum ramp rates $\left(R_{\max }\right)$ in about $8 \mathrm{~s}$; DBA reduces $R_{\max }$ by $\sim 30 \%$ from $\sim 1{ }^{\circ} \mathrm{C} / \mathrm{m}$ to $\sim 0.7{ }^{\circ} \mathrm{C} / \mathrm{min}$.

A simple model is used to estimate the generated heat over time, based on the following assumptions: (1) The temperature of the cell is represented by the thermocouple measurement; (2) The convective heat transfer is considered and the radiative heat transfer is ignored [30]; 
and (3) the heat capacity of the added electrolyte or DBA is much smaller than that of the cell components. The heat generation rate $\left(q^{\prime}\right)$ can be calculated by:

$$
q^{\prime}=\left(m_{e} C_{P e}+m_{s} C_{P s}\right) \frac{d T}{d t}+A h\left(T-T_{a m b}\right)
$$

where $m$ indicates mass and $C_{P}$ indicates specific heat; subscript " $e$ " stands for the electrode stack containing electrolyte and subscript " $s$ " stands for the stainless steel case together with the nail; $T$ is the temperature of the cell and $T_{\text {amb }}$ is ambient temperature; $A$ is the surface area exposed to air, including both the cell and the nail, and $h$ is the convective coefficient. The values of these parameters are given in Table 1. The accumulated heat $(q)$ is calculated by:

$$
q=\int_{0}^{t}\left[\left(m_{e} C_{P e}+m_{s} C_{P s}\right) \frac{d T}{d t}+A h\left(T-T_{a m b}\right)\right] d t
$$

Table 1 The parameters used in Equations (1) and (2)

\begin{tabular}{|c|c|c|c|c|c|c|}
\hline$m_{\mathrm{e}}(\mathrm{kg})$ & $m_{\mathrm{s}}(\mathrm{kg})$ & $C_{\mathrm{Pe}}(\mathrm{J} / \mathrm{kg} \mathrm{K})$ & $C_{\mathrm{Ps}}(\mathrm{J} / \mathrm{kg} \mathrm{K})$ & $A\left(\mathrm{~m}^{2}\right)$ & $h\left(\mathrm{~W} / \mathrm{m}^{2} \mathrm{~K}\right)$ & $T_{\mathrm{amb}}(\mathrm{K})$ \\
\hline $2.2 \times 10^{-3}$ & $7.2 \times 10^{-3}$ & $1100[31]$ & 500 & $1.8873 \times 10^{-3}$ & $7.9[32]$ & 298 \\
\hline
\end{tabular}

Fig. 1d shows the generated heat of reference and DBA-modified cells, obtained from Eq.(2); the inset shows the heat generation rate obtained from Eq.(1). The heat generation in the first $20 \mathrm{~min}$ is $0.23 \mathrm{Wh}$ for the reference cell and $0.15 \mathrm{Wh}$ for the DBA-modified cell, respectively. The addition of $4 \mathrm{wt} \% \mathrm{DBA}$ leads to about $1 / 3$ reduction in generated heat during the time period of measurement. Eventually, the DBA-modified cell may generate about the same amount of heat as the reference cell, but it may not be particularly critical to thermal runaway mitigation, since the peak temperature is reached in the first few minutes. 
Fig. 1e shows typical nail penetration temperature profiles of unmodified LIR-2450 cells at different SOC. The heat generation is analyzed by Eq.(2) and the result is displayed in Fig. 1f. Compared with the peak temperatures of the modified reference cell (Fig. 1b), $\Delta T_{\max }$ of a fully charged unmodified cell is slight higher and the post-peak temperature decrease rate is somewhat lower, which may be attributed to the resistance increase during reassembly. By adding $4 \mathrm{wt} \%$ DBA, the temperature profile of a fully charged cell is similar to that of the reference cell at $50 \%$ SOC; that is, nearly $50 \%$ of the stored electricity cannot be converted to thermal energy.

The impact test on LIR-2450 cells with embedded TRR-containing packages confirms that the TRR could be sealed under working condition and be released as the cell is damaged. The DBA amount is $5 \mathrm{wt} \%$ of the total mass of electrodes, current collectors, separator, and electrolyte. Fig. 2a displays the cell components before assembly and after impact. The TRR package is broken apart upon impact. The temperature profiles of reference and DBAmodified cells are shown in Fig. 2b; each group contains three cell samples. The heat generation shown in Fig. 2c is calculated through Eq.(2). It can be seen that for all the samples, $\Delta T_{\max }$ in impact test is smaller than that in nail penetration test, because the nail penetration leads to a more intense internal shorting. In impact test, DBA decreases $\Delta T_{\max }$ by about $50 \%$, similar to the nail penetration test. 

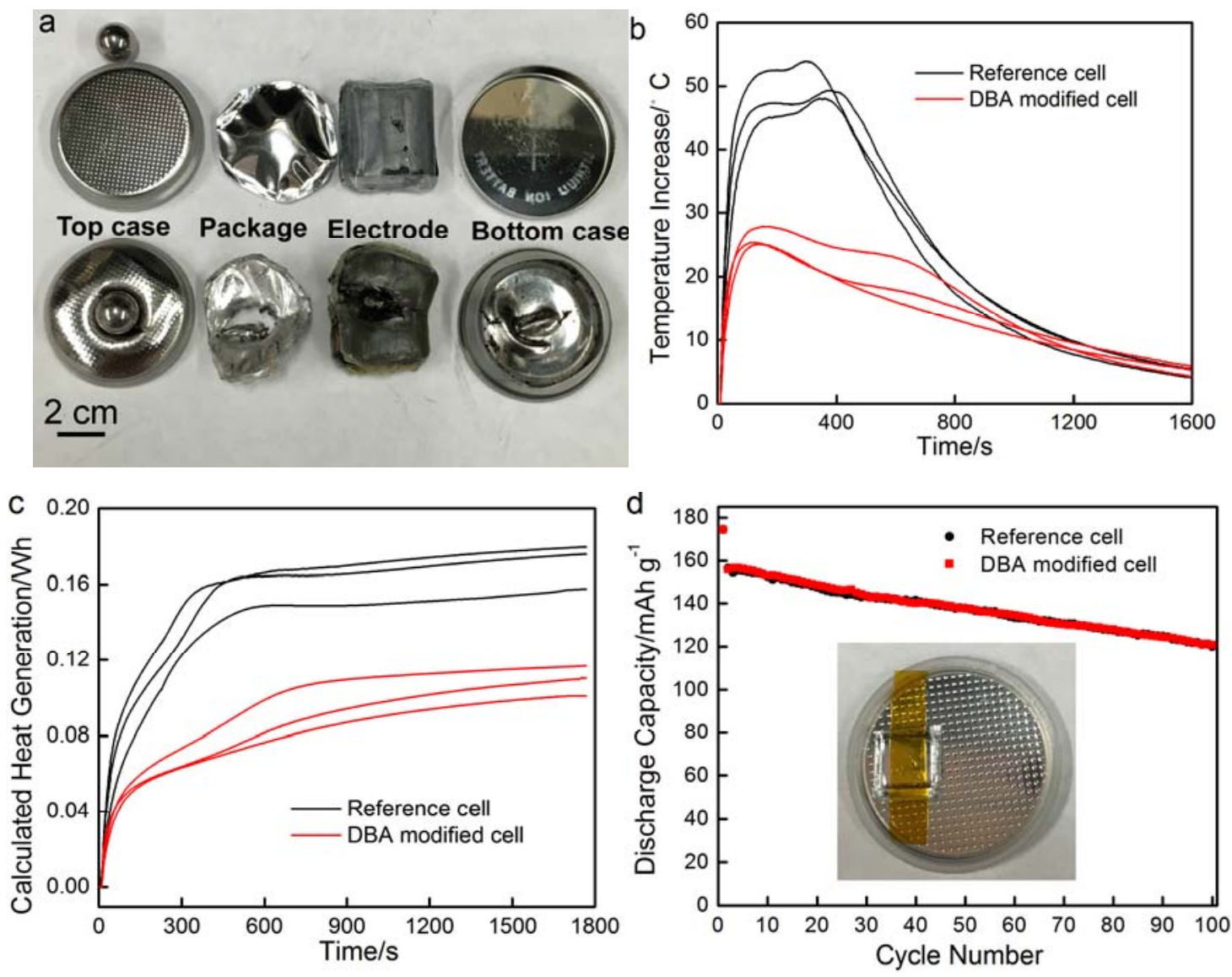

Fig. 2 (a) Cell components before (top) and after (bottom) impact. (b) Temperature profiles of six LIR-2450 cells embedded with TRR packages.

(c) Calculated heat generation of the six LIR-2450 cells. (d) Cycling performance of coin cells with embedded TRR packages; the inset is a photo of a modified coin cell

The TRR package is made from PAP trilayer material, because the polyethylene can be conveniently heat sealed; the dense aluminum middle layer offers an ultra-low permeability; and the outer polyester layer insulates the aluminum layer. Figure 2d shows the cycling performance of coin cells with DBA-containing packages. The packages have little influence on the cell capacity up to 100 cycles. 
To investigate the working mechanism of DBA, the interaction of DBA with electrodes is studied. As DBA is dropped on the cathode and anode harvested from a LIR-2450 cell fully charged to $4.3 \mathrm{~V}$, local temperature is monitored continuously. Upon exposure to DBA, an abrupt temperature increase is observed on the charged cathode, yet the temperature of anode remains nearly constant (Fig. 3a), indicating that a DBA-cathode interaction takes place. Charged cathode disks are then soaked up in DBA. After the cathodes are thoroughly washed to remove remaining DBA, they are reassembled into coin cells with pristine electrolyte. The specific discharge capacities of the two types of reassembled cells are $164 \mathrm{mAh} / \mathrm{g}$ and 149.2 $\mathrm{mAh} / \mathrm{g}$, respectively (Fig. 3b). For the reassembled reference cell, the initial voltage drop is due to the voltage relaxation. The voltage drop of the cell containing DBA-treated cathode is larger than that of the reference cell. In a parallel test, charged cathode materials were allowed to react with DBA in order to determine the reaction products, but no change is observed in the ${ }^{1} \mathrm{H}$ NMR spectra (Supplementary Fig. S1) and mass spectra (Supplementary Fig. S2) of DBA before and after the reaction, suggesting that the reaction products of DBA are not in liquid phase. Moreover, no gas generation is observed during the reaction of DBA with the charged cathode. It is possible that a solid layer of reaction products is deposited on the cathode surface. The initial voltage drop and the capacity loss might be attributed to this additional resistive layer. Note that the DBA-treated cathode could still deliver $91 \%$ of the discharge capacity of the reference cathode, and the fact that DBA-cathode reaction is exothermic (Fig.3a) is against the observed reduction in $\Delta T_{\max }$. Therefore, the chemical 
reactions between the cathode and DBA should not be a major factor that influences the heat generation in nail penetration and impact tests.
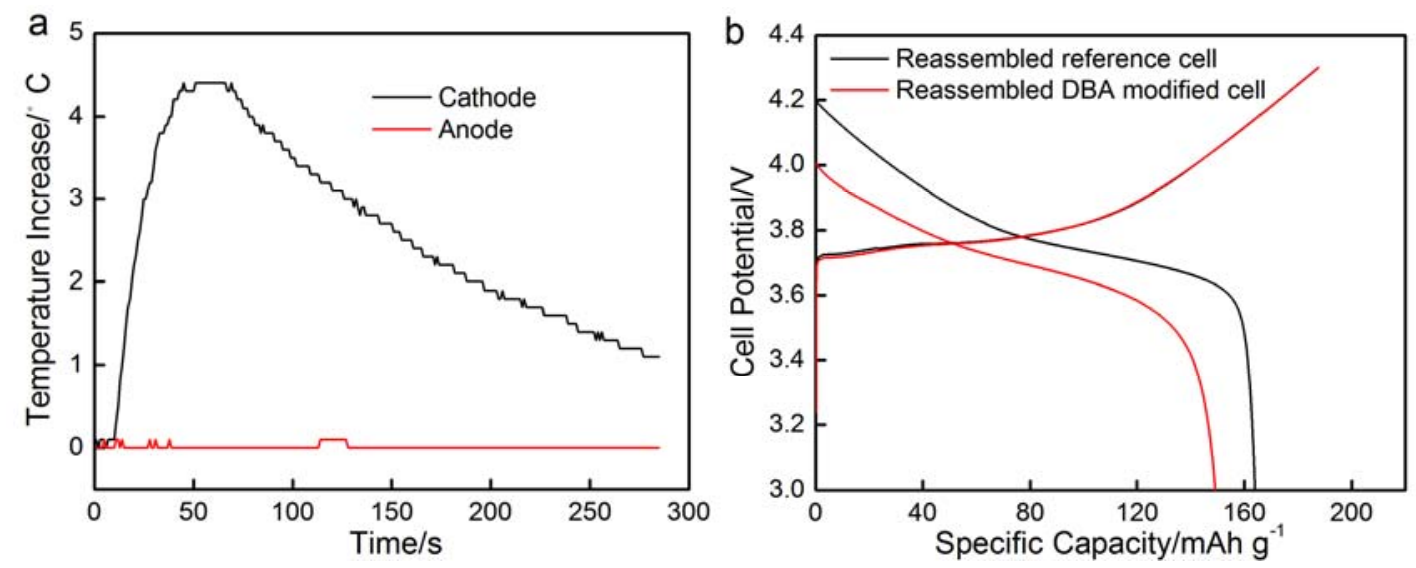

Fig. 3 (a) Typical temperature profiles of cathode and anode exposed to DBA. (b) Typical Charge-discharge curves of reassembed reference and DBA-modified cells at C/10

The effects of DBA addition on the electrolyte are investigated. As shown in Fig. 4a, the ionic conductivity of pristine electrolyte is $9.23 \mathrm{mS} / \mathrm{cm}$. The $5 \mathrm{wt} \%$ and $10 \mathrm{wt} \% \mathrm{DBA}-$ modified electrolytes have reduced ionic conductivity of $7.59 \mathrm{mS} / \mathrm{cm}$ and $6.38 \mathrm{mS} / \mathrm{cm}$, respectively. Coin cells assembled with pristine electrolyte as well as $5 \mathrm{wt} \%$ or $10 \mathrm{wt} \%$ DBA containing electrolyte are cycled at $1 \mathrm{C}$ and the cell potentials dynamics over time are shown in Fig. 4b. The cell with $5 \mathrm{wt} \%$ DBA has a larger polarization and a greatly reduced capacity compared to the reference cell; the cell with $10 \mathrm{wt} \%$ DBA has the lowest capacity and cannot be normally charged and discharged. Clearly, DBA significantly increases the cell impedance. EIS measurements are performed on the cells before and after 5 charge-discharge cycles.

Figures. 4c and 4d show the Nyquist plots, equivalent circuits, and fitted curves, with $R_{\mathrm{S}}$ being the electrolyte resistance, $R_{\text {sei }}$ the solid electrolyte interface (SEI) resistance, and $R_{\mathrm{ct}}$ the 
charge-transfer resistance [33]. Table 2 shows the resistance values according to the fitting results of the equivalent circuit. It is evident that the DBA-modified cell has not only a larger electrolyte resistance, but also much higher SEI and charge-transfer resistances.
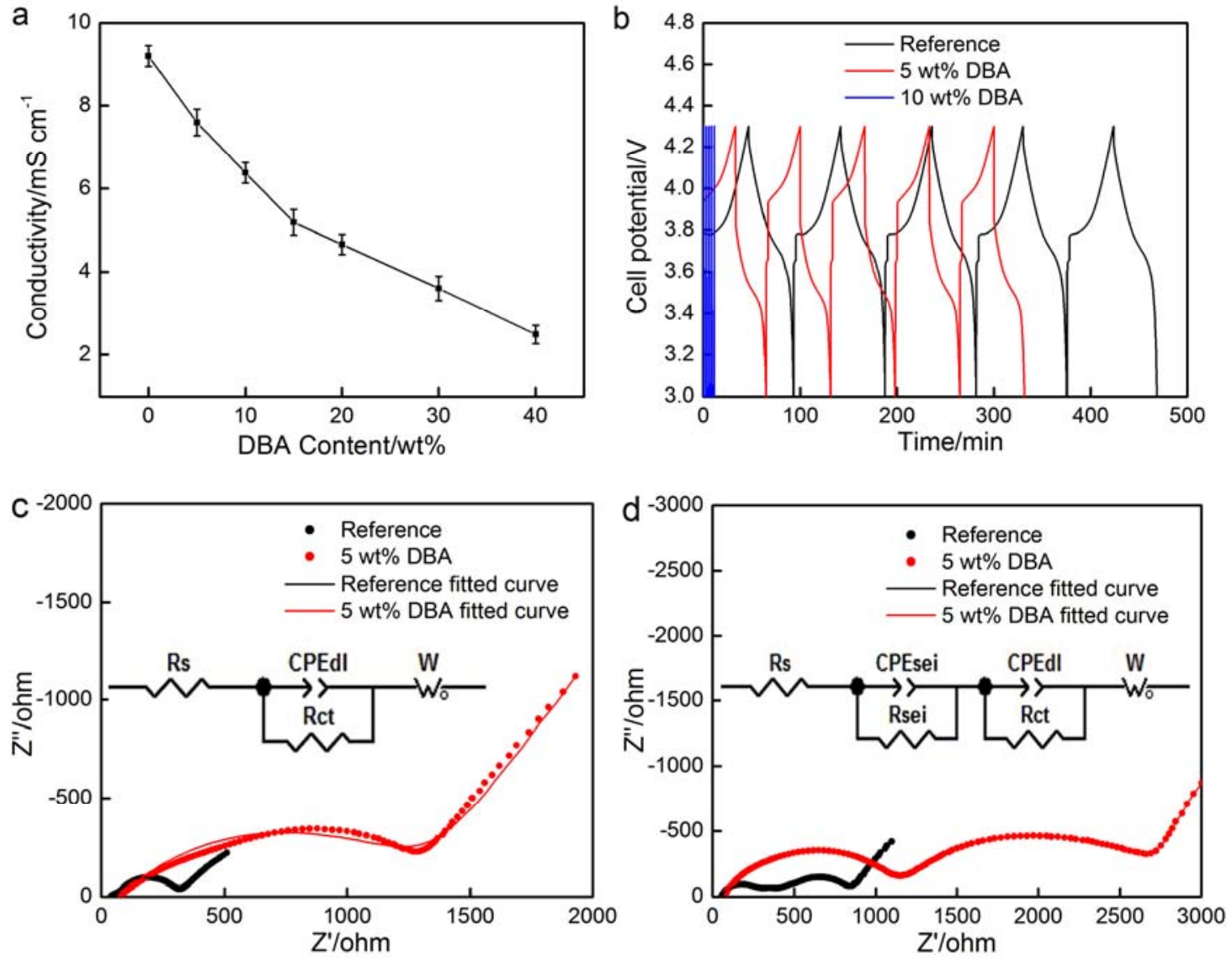

Fig. 4 (a) Ionic conductivity of DBA-modified electrolyte. (b) Typical voltage profiles of the reference and DBA-modified cells. Nyquist plots, equivalent circuits, and fitting plots: (c) immediately after reassembly and (d) after 5 charge-discharge cycles.

Table 2 Resistance values of equivalent circuits in EIS measurement

\begin{tabular}{|c|c|c|c|c|c|}
\hline & \multicolumn{2}{|c|}{ After assembly } & \multicolumn{3}{c|}{ After 5 cycles } \\
\cline { 2 - 6 } & $\mathrm{R}_{\mathrm{s}}(\Omega)$ & $\mathrm{R}_{\mathrm{ct}}(\Omega)$ & $\mathrm{R}_{\mathrm{s}}(\Omega)$ & $\mathrm{R}_{\text {sei }}(\Omega)$ & $\mathrm{R}_{\mathrm{ct}}(\Omega)$ \\
\hline Reference cell & 50 & 250 & 58 & 254 & 450 \\
\hline DBA-modified cell & 75 & 1050 & 65 & 1040 & 1700 \\
\hline
\end{tabular}



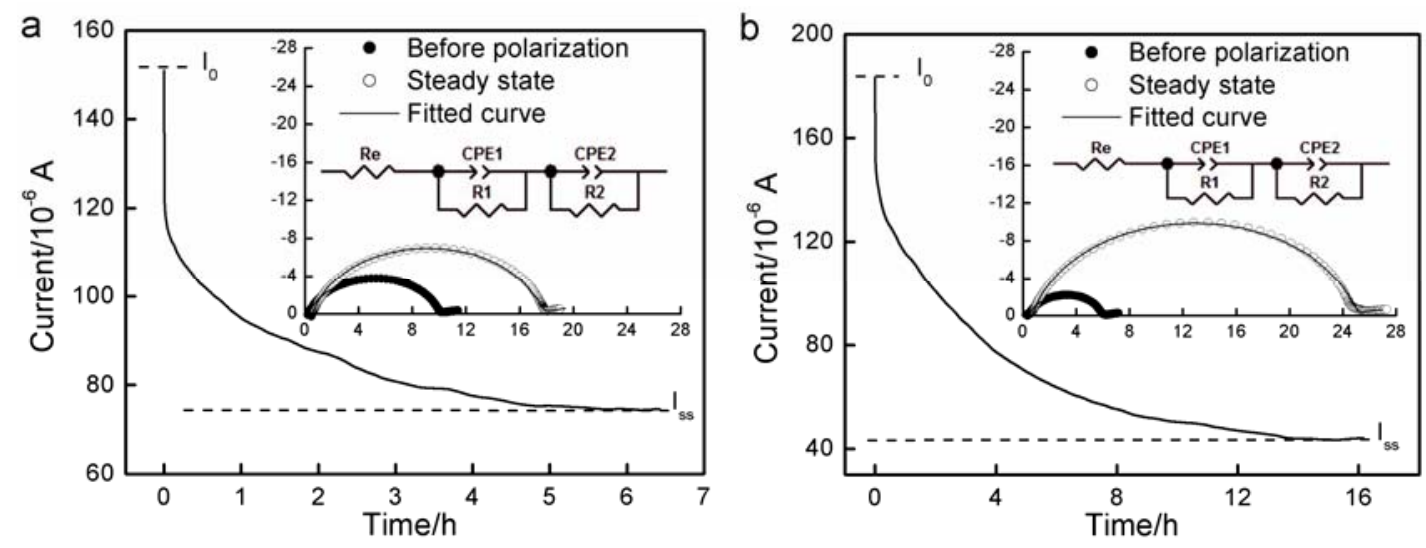

Fig. 5 Polarization curves of Li metal symmetric cells with (a) pristine electrolyte and (b) electrolyte containing $5 \mathrm{wt} \% \mathrm{DBA}$; the insets show the Nyquist plots before and after polarization.

Table 3 The measurement results of $\mathrm{Li}^{+}$transference numbers

\begin{tabular}{|l|c|c|c|c|c|c|c|}
\hline & $I_{0}$ & $I_{\mathrm{ss}}$ & $R \mathrm{e}_{0}$ & $R \mathrm{e}_{\mathrm{Ss}}$ & $R_{0}$ & $R_{\mathrm{sS}}$ & $t_{\mathrm{Li}}{ }^{+}$ \\
\hline Reference cell & 151.102 & 74.454 & 0.271 & 0.548 & 12.345 & 22.032 & 0.48 \\
\hline DBA-modified cell & 183.487 & 43.687 & 0.402 & 0.715 & 8.304 & 28.218 & 0.23 \\
\hline
\end{tabular}

The effect of DBA addition on the $\mathrm{Li}^{+}$transport property is further investigated through the measurement of $\mathrm{Li}^{+}$transference numbers by a potentiostatic polarization method $[34,35]$, in which a constant voltage of $10 \mathrm{mV}(\Delta V)$ is applied on a Li metal symmetric cell. During the polarization, the current drops from the initial value $\left(I_{0}\right)$ to a steady-state value $\left(I_{\mathrm{ss}}\right)$. Figures. 5a and $\mathbf{5 b}$ display the current drop with time, and the insets show the Nyquist plots from EIS measurements before and after polarization. In the corresponding equivalent circuit, $R_{1}$ and $R_{2}$ are the Li-electrolyte interfacial resistances, and $R_{\mathrm{e}}$ is the electrolyte resistance [35, 36]. The $\mathrm{Li}^{+}$transference numbers $t_{L i}{ }^{+}$is given by [37]:

$$
t_{L i^{+}}=\frac{I_{s s}}{I_{0}}\left(\frac{\Delta V-I_{0} R_{0}}{\Delta V-I_{s s} R_{s s}}\right)
$$


where $R_{0}$ and $R_{\mathrm{s}}$ equal to the summations of $R_{1}$ and $R_{2}$ before and after polarization, respectively. Table 3 shows the values of $I_{0}$ and $I_{\mathrm{ss}}$ during polarization, the resistance values from the fitting results, and the calculated $\mathrm{Li}^{+}$transference numbers of reference and DBAmodified electrolyte. The $\mathrm{Li}^{+}$transference numbers of reference electrolyte is 0.48 , which is consistent with the data in open literature [38]. The addition of $5 \mathrm{wt} \% \mathrm{DBA}$ decreases the $\mathrm{Li}^{+}$ transference number to 0.23 .

The testing data show that the addition of DBA increases the electrolyte resistance and the charge transfer resistance, and decreases the $\mathrm{Li}^{+}$transference number, all of which would suppress $\mathrm{Li}^{+}$transportation, suggesting that the modification of electrolyte is a major reason of the hindered heat generation and the reduced $\Delta T_{\max }$ in nail penetration and impact tests. The increased resistances and reduced $\mathrm{Li}^{+}$transference number may result from the Lewis base characteristic of DBA. Previous studies reported that adding Lewis acid to an electrolyte could improve the conductivity by forming complex with salt anions [39]. The Lewis acid serves as an anion receptor, enhances the dissociation of ion pairs, and increases the population of free cations [40]. The dissociation of ion pairs contributes to a high $\mathrm{Li}^{+}$ transference number. DBA is a Lewis base and an electron donor, which may repel the PF6 anions and decrease the dissociation of $\mathrm{Li}^{+}$solvation shell and $\mathrm{PF}^{-}$pairs, resulting in the decrease in $\mathrm{Li}^{+}$transference number and conductivity.

The current study on coin cells demonstrate the basic concept of including DBA in battery cells. It is envisioned that the conditions in large-sized pouch cells are different from coin 
cells, in terms of cell size, mass, electrolyte-electrode mass ratio, among others. Using TRR for thermal-runaway mitigation of pouch cells will be an important topic of our future study.

\section{Conclusions}

Dibenzylamine (DBA) is identified as a promising thermal runaway retardant (TRR) of lithium-ion batteries (LIBs). Upon nail penetration or impact, the temperature increase of a fully charged LIR-2450 LIB cell with $4 \mathrm{wt} \%$ DBA could be reduced by $\sim 50 \%$. Embedding DBA-containing packages in coin cells does not affect the cell capacity and the cycling performance up to 100 cycles. Charged anode does not react with DBA. Exothermic reactions between DBA and charged cathode are observed, but it is not a governing factor of the reduced heat generation of damaged cells. The major working mechanism of DBA is associated with the increase in electrolyte and charge transfer resistances as well as the decrease in $\mathrm{Li}^{+}$transference number. 


\section{Acknowledgement}

This research is supported by Advanced Research Projects Agency - Energy (ARPA-E) under Grant No. DE-AR0000396, for which we are grateful to Dr. Ping Liu, Dr. John Lemmon, Dr. Grigorii Soloveichik, Dr. Chris Atkinson, and Dr. Dawson Cagle. Special thanks are also due to Dr. Jiang Fan and Dr. Dengguo Wu at the American Lithium Energy Corporation for the help with lithium-ion battery design and processing. 


\section{References}

[1] L. Lu, X. Han, J. Li, J. Hua, M. Ouyang, A review on the key issues for lithium-ion battery management in electric vehicles, J. Power Sources, 226 (2013) 272-288.

[2] D.P. Finegan, M. Scheel, J.B. Robinson, B. Tjaden, I. Hunt, T.J. Mason, J. Millichamp, M. Di Michiel, G.J. Offer, G. Hinds, D.J.L. Brett, P.R. Shearing, In-operando high-speed tomography of lithium-ion batteries during thermal runaway, Nat. Commun., 6 (2015).

[3] P.G. Balakrishnan, R. Ramesh, T. Prem Kumar, Safety mechanisms in lithium-ion batteries, J. Power Sources, 155 (2006) 401-414.

[4] P. Arora, Z. Zhang, Battery separators, Chem. Rev., 104 (2004) 4419-4462.

[5] F.C. Laman, M.A. Gee, J. Denovan, Impedance studies for separators in rechargeable lithium batteries, J. Electrochem. Soc., 140 (1993) L51-L53.

[6] M. Baginska, B.J. Blaiszik, R.J. Merriman, N.R. Sottos, J.S. Moore, S.R. White, Autonomic shutdown of lithium-ion batteries using thermoresponsive microspheres, Adv.Energy Mater., 2 (2012) 583-590.

[7] X.M. Feng, X.P. Ai, H.X. Yang, A positive-temperature-coefficient electrode with thermal cut-off mechanism for use in rechargeable lithium batteries, Electrochem. Commun., 6 (2004) 1021-1024.

[8] H. Zhong, C. Kong, H. Zhan, C. Zhan, Y. Zhou, Safe positive temperature coefficient composite cathode for lithium ion battery, J. Power Sources, 216 (2012) 273-280. 
[9] J. Li, J.G. Chen, H. Lu, M. Jia, L.X. Jiang, Y.Q. Lai, Z.A. Zhang, A Positive-

Temperature-coefficient layer based on Ni-mixed poly(vinylidene fluoride) composites for $\mathrm{LiFePO}_{4}$ electrode, Int. J. Electrochem. Sci., 8 (2013) 5223-5231.

[10] H. Zhang, J. Pang, X. Ai, Y. Cao, H. Yang, S. Lu, Poly(3-butylthiophene)-based positive-temperature-coefficient electrodes for safer lithium-ion batteries, Electrochim. Acta, 187 (2016) 173-178.

[11] T. Yim, M.S. Park, S.G. Woo, H.K. Kwon, J.K. Yoo, Y.S. Jung, K.J. Kim, J.S. Yu, Y.J. Kim, Self-extinguishing lithium ion batteries based on internally embedded fire-extinguishing microcapsules with temperature-responsiveness, Nano Lett., 15 (2015) 5059-5067.

[12] L. Xia, D. Wang, H. Yang, Y. Cao, X. Ai, An electrolyte additive for thermal shutdown protection of Li-ion batteries, Electrochem. Commun., 25 (2012) 98-100.

[13] D.P. Abraham, E.P. Roth, R. Kostecki, K. McCarthy, S. MacLaren, D.H. Doughty, Diagnostic examination of thermally abused high-power lithium-ion cells, J. Power Sources, 161 (2006) 648-657.

[14] J. Hu, Z. Jin, H. Zhong, H. Zhan, Y. Zhou, Z. Li, A new phosphonamidate as flame retardant additive in electrolytes for lithium ion batteries, J. Power Sources, 197 (2012) 297300. 
[15] Y. Lai, C. Ren, H. Lu, Z. Zhang, J. Li, Compatibility of diphenyloctyl phosphate as flame-retardant additive with $\mathrm{LiNi}_{1 / 3} \mathrm{Co}_{1 / 3} \mathrm{Mn}_{1 / 3} \mathrm{O}_{2} /$ artificial graphite cells, J. Electrochem. Soc., 159 (2012) A1267-A1272.

[16] I.J. Park, T.H. Nam, J.G. Kim, Diphenyloctyl phosphate as a solid electrolyte interphase forming additive for Li-ion batteries, J. Power Sources, 244 (2013) 122-128.

[17] R.P. Dunn, J. Kafle, F.C. Krause, C. Hwang, B.V. Ratnakumar, M.C. Smart, B.L. Lucht, Electrochemical analysis of li-ion cells containing triphenyl phosphate, J. Electrochem. Soc., 159 (2012) A2100-A2108.

[18] N. Ohmi, T. Nakajima, Y. Ohzawa, M. Koh, A. Yamauchi, M. Kagawa, H. Aoyama, Effect of organo-fluorine compounds on the thermal stability and electrochemical properties of electrolyte solutions for lithium ion batteries, J. Power Sources, 221 (2013) 6-13.

[19] B. Wu, F. Pei, Y. Wu, R. Mao, X. Ai, H. Yang, Y. Cao, An electrochemically compatible and flame-retardant electrolyte additive for safe lithium ion batteries, J. Power Sources, 227 (2013) 106-110.

[20] D. Aurbach, O. SrurLavi, C. Ghanty, M. Dixit, O. Haik, M. Talianker, Y. Grinblat, N. Leifer, R. Lavi, D.T. Major, G. Goobes, E. Zinigrad, E.M. Erickson, M. Kosa, B. Markovsky, J. Lampert, A. Volkov, J.Y. Shin, A. Garsuch, Studies of aluminum-doped $\mathrm{LiNi}_{0.5} \mathrm{Co}_{0.2} \mathrm{Mn}_{0.3} \mathrm{O}_{2}$ : dlectrochemical behavior, aging, structural transformations, and thermal characteristics, J. Electrochem. Soc., 162 (2015) A1014-A1027. 
[21] A. Aboulaich, K. Ouzaouit, H. Faqir, A. Kaddami, I. Benzakour, I. Akalay, Improving thermal and electrochemical performances of $\mathrm{LiCoO}_{2}$ cathode at high cut-off charge potentials by MF3 (M=Ce, Al) coating, Mater. Res. Bull., 73 (2016) 362-368.

[22] X. Bian, Q. Fu, X. Bie, P. Yang, H. Qiu, Q. Pang, G. Chen, F. Du, Y. Wei, Improved electrochemical performance and thermal stability of $\mathrm{Li}$-excess $\mathrm{Li}_{1.18} \mathrm{Co}_{0.15} \mathrm{Ni}_{0.15} \mathrm{Mn}_{0.52} \mathrm{O}_{2}$ cathode material by $\mathrm{Li}_{3} \mathrm{PO}_{4}$ surface coating, Electrochim. Acta, 174 (2015) 875-884.

[23] D. Wang, X. Li, Z. Wang, H. Guo, X. Chen, X. Zheng, Y. Xu, J. Ru, Multifunctional $\mathrm{Li}_{2} \mathrm{O}-2 \mathrm{~B}_{2} \mathrm{O}_{3}$ coating for enhancing high voltage electrochemical performances and thermal stability of layered structured $\mathrm{LiNi}_{0.5} \mathrm{Co}_{0.2} \mathrm{Mn}_{0.3} \mathrm{O}_{2}$ cathode materials for lithium ion batteries, Electrochim. Acta, 174 (2015) 1225-1233.

[24] Y.S. Lee, W.K. Shin, A.G. Kannan, S.M. Koo, D.W. Kim, Improvement of the cycling performance and thermal stability of lithium-ion cells by double-layer coating of cathode materials with $\mathrm{Al}_{2} \mathrm{O}_{3}$ nanoparticles and conductive polymer, ACS Appl. Mater. Interfaces, 7 (2015) 13944-13951.

[25] J.J. Chen, Z.D. Li, H.F. Xiang, W.W. Wu, S. Cheng, L.J. Zhang, Q.S. Wang, Y.C. Wu, Enhanced electrochemical performance and thermal stability of a $\mathrm{CePO}_{4}$-coated $\mathrm{Li}_{1.2} \mathrm{Ni}_{0.13} \mathrm{Co}_{0.13} \mathrm{Mn}_{0.54} \mathrm{O}_{2}$ cathode material for lithium-ion batteries, RSC Advances, 5 (2015) 3031-3038. 
[26] Y. Shi, M. Zhang, D. Qian, Y.S. Meng, Ultrathin $\mathrm{Al}_{2} \mathrm{O}_{3}$ coatings for improved cycling performance and thermal stability of $\mathrm{LiNi}_{0.5} \mathrm{Co}_{0.2} \mathrm{Mn}_{0.3} \mathrm{O}_{2}$ cathode material, Electrochim. Acta, 203 (2016) 154-161.

[27] A.V. Le, M. Wang, Y. Shi, D. Noelle, Y. Qiao, W. Lu, Effects of additional multiwall carbon nanotubes on impact behaviors of $\mathrm{LiNi}_{0.5} \mathrm{Mn}_{0.3} \mathrm{Co}_{0.2} \mathrm{O}_{2}$ battery electrodes, J. Appl.

Phys., 118 (2015) 085312.

[28] A.V. Le, M. Wang, Y. Shi, D.J. Noelle, Y. Qiao, Heat generation of mechanically abused lithium-ion batteries modified by carbon black micro-particulates, J. Phys. D: Appl. Phys., 48 (2015) 385501-385507.

[29] M. Wang, A.V. Le, Y. Shi, D.J. Noelle, H. Yoon, M. Zhang, Y.S. Meng, Y. Qiao, Effects of angular fillers on thermal runaway of lithium-ion battery, J. Mater. Sci. Tech., (2016) in press.

[30] C. Lan, X. Jian, Y. Qiao, Y. Ma, Thermal management for high power lithium-ion battery by minichannel aluminum tubes, Appl. Thermal Eng., (2016) in press

[31] X. Feng, C. Weng, M. Ouyang, J. Sun, Online internal short circuit detection for a large format lithium ion battery, Appl. Energy, 161 (2016) 168-180.

[32] R. Zhao, J. Liu, J. Gu, Simulation and experimental study on lithium ion battery short circuit, Appl. Energy, 173 (2016) 29-39.

[33] J. Ni, H. Zhou, J. Chen, X. Zhang, Improved electrochemical performance of layered $\mathrm{LiNi}_{0.4} \mathrm{Co}_{0.2} \mathrm{Mn}_{0.4} \mathrm{O}_{2}$ via $\mathrm{Li}_{2} \mathrm{ZrO}_{3}$ coating, Electrochim. Acta, 53 (2008) 3075-3083. 
[34] J. Zhao, L. Wang, X. He, C. Wan, C. Jiang, Determination of lithium-ion transference numbers in $\mathrm{LiPF}_{6}-\mathrm{PC}$ solutions based on electrochemical polarization and NMR measurements, J. Electrochem. Soc., 155 (2008) A292-A296.

[35] S. Zugmann, M. Fleischmann, M. Amereller, R.M. Gschwind, H.D. Wiemhöfer, H.J. Gores, Measurement of transference numbers for lithium ion electrolytes via four different methods, a comparative study, Electrochim. Acta, 56 (2011) 3926-3933.

[36] M. Riley, P.S. Fedkiw, S.A. Khan Transport properties of lithium hectorite-based composite electrolytes, J. Electrochem. Soc., 149 (2002) A667-A674.

[37] J. Evans, C.A. Vincent, P.G. Bruce, Electrochemical measurement of transference numbers in polymer electrolytes, Polymer, 28 (1987) 2324-2328.

[38] C. Capiglia, Y. Saito, H. Kageyama, P. Mustarelli, T. Iwamoto, T. Tabuchi, H. Tukamoto, ${ }^{7} \mathrm{Li}$ and ${ }^{19} \mathrm{~F}$ diffusion coefficients and thermal properties of non-aqueous electrolyte solutions for rechargeable lithium batteries, J. Power Sources, 81-82 (1999) 859862.

[39] H.S. Lee, X. Sun, X.Q. Yang, J. McBreen, Synthesis and study of new cyclic boronate additives for lithium battery electrolytes, J. Electrochem. Soc., 149 (2002) A1460-A1465. [40] X. Sun, H.S. Lee, X.Q. Yang, J. McBreen, Comparative studies of the electrochemical and thermal stability of two types of composite lithium battery electrolytes using boron based anion receptors, J. Electrochem. Soc., 146 (1999) 3655-3659. 